\title{
Effect of complexity on marine ecosystem models
}

\author{
Elizabeth A. Fulton ${ }^{1, *}$, Anthony D. M. Smith ${ }^{1}$, Craig R. Johnson ${ }^{2}$ \\ ${ }^{1}$ CSIRO Division of Marine Research, GPO Box 1538, Hobart, Tasmania 7001, Australia \\ ${ }^{2}$ School of Zoology and Tasmanian Aquaculture and Fisheries Institute (TAFI), University of Tasmania, GPO Box 252-05, \\ Hobart, Tasmania 7001, Australia
}

\begin{abstract}
Ecosystem rather than species management has become an explicit part of policies that feature in international treaties and national legislation. Many of the tools that will be needed to fulfil the requirements of these policies are still in an early stage of development. One such tool is trophic ecosystem modelling. These models have been put forward to aid system-level understanding and provide insight into the potential impacts of human activities. Despite this, there are many gaps in knowledge of their strengths and weaknesses. In particular, little is known about the effect of the level of detail in a model on its performance. There has been some consideration of the effects of model formulation, as well as the effects of the physical, biological and chemical scope of multispecies and ecosystem models on their performance. A review of existing research indicates that there is a humped relationship between model detail and performance for these models, and that there are some guiding principles to consider during model development. This review gives some insight into which model structures and assumptions are likely to aid understanding and management, and which may be unnecessary. Further, it provides some understanding of whether some models can capture properties of real systems that other models cannot. The main recommendation is that the use of a single 'ultimate' ecosystem model is ill-advised, while the comparative and confirmatory use of multiple 'minimum-realistic' models is strongly recommended.
\end{abstract}

KEY WORDS: Ecosystem - Multispecies $\cdot$ Model $\cdot$ Complexity $\cdot$ Model structure $\cdot$ Model scope Resale or republication not permitted without written consent of the publisher

\section{INTRODUCTION}

During the last $30 \mathrm{yr}$, with every push to understand entire ecosystems rather than isolated components, ecosystem models have become a popular tool (Watt 1975, Halfon 1979, Walters et al. 1997, Sainsbury et al. 2000). However, complex general models have often acquired a poor reputation (Jørgensen et al. 1992), primarily because of 2 factors. First, these models are often so large and complex that they may not be costefficient, with the majority of the modelling resources spent in development and maintenance rather than on their application (Watt 1975). Second, complexity introduced for the sake of completeness accomplishes nothing if the resulting model is actually of poor quality (O'Neill 1975, Silvert 1981, DeCoursey 1992). While modern computing power makes ecosystem models attractive, as computational restraints are lifted (Beck

*Email: beth.fulton@csiro.au
1999), this does not solve the problems of uncertain model specification, parameterisation and system understanding, or the effects of model structure and detail on model performance (Silvert 1981, Jørgensen 1994). These areas of modelling still require much attention and the need becomes more urgent with increasing pressure on scientists and managers for 'whole system' approaches, predictions and policies.

\section{ECOSYSTEM MODELS}

Terminology associated with ecosystem models is confusing, in that ecosystem models can refer to everything from total system models (dealing with biotic components from multiple tropic levels as well as abiotic components and forcing) to models that focus solely on fisheries (the 'top end' of the web) or water 


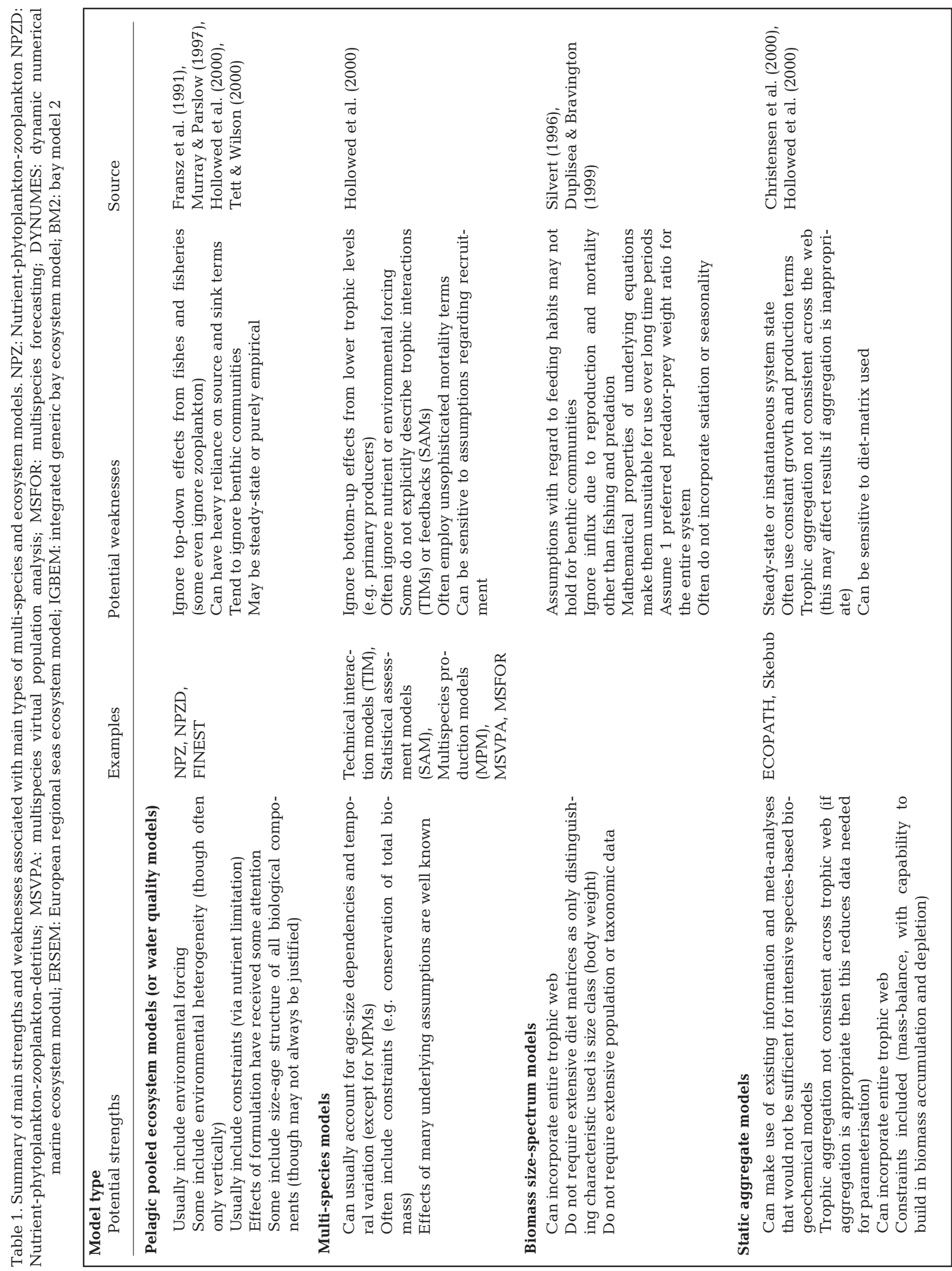




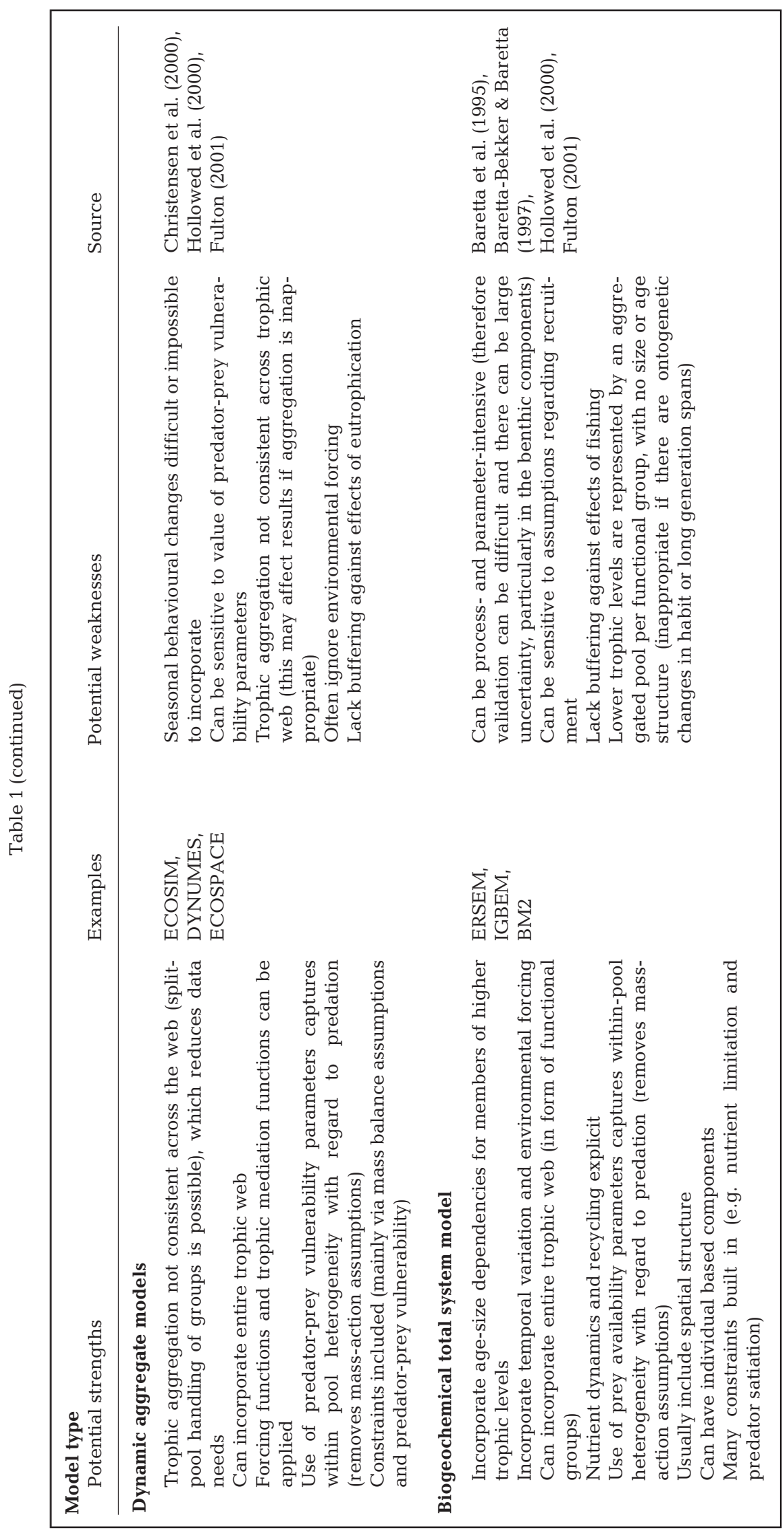

quality (the 'bottom end' of the web). Here we use the term ecosystem model to refer to total system models rather than those multispecies models tied to one end of the food web or the other.

Within the last few decades, increasing computer power and a shift in the focus of scientific and political thought has lead to a rapid growth in the number of multispecies and ecosystem models in existence (Silvert 1981, Breckling \& Müller 1994). The majority of published and applied multispecies models tend to concentrate around fishes or nutrients and in both cases, the history of model development can be 'characterised by the growing intricacy of their internal structure' (Fransz et al. 1991). There have been a number of attempts at producing trophic 'whole ecosystem' models for the marine environment, including the cove model of Patten et al. (1975), the multispecies model of Andersen \& Ursin (1977), the fjord model of Bax \& Eliassen (1990), the ECOPATH with ECOSIM model (Christensen et al. 2000); the European regional seas ecosytem (ERSEM I [Baretta et al. 1995] and II [Baretta-Bekker \& Baretta 1997] models; the integrated generic bay ecosystem [IGBEM]) model and Bay Model 2 (BM2) (Fulton 2001). Nevertheless, compared with the widespread use of water quality and fisheries multispecies models, the use of ecosystem models remains limited. As a result, there is still a lot of scope for the development of a thorough understanding of the implications of model structure on performance for these kinds of models.

The various types of multispecies and ecosystem models each have associated advantages and problems (Table 1), but there is a list of features and potential drawbacks common to them all. In general, such models improve our understanding of systems by reflecting the 2-way nature of system dynamics. Human impact on one part of a system can spread to 
other parts of the system, but system feedbacks and interrelations can also mean that an impact can have unexpected consequences even for those groups directly affected by anthropogenic activities (Hollowed et al. 2000, Fulton 2001, Mace 2001). There are also a number of potential problems common to multispecies and ecosystem models: (1) they inevitably require more information than single-species models (which incur associated costs); (2) they are more likely to suffer from issues about optimal complexity (i.e. what groups and processes should be included); (3) operational objectives and monitoring indices can be hard to define for the real systems to be modelled; (4) it can be difficult to define appropriate indices to summarise model output; (5) there are often alternative hypotheses about system structure and function (Silvert 1981, Jørgensen 1994, Mace 2001). These features are particularly important when dealing with ecosystem models. However, as multispecies and ecosystem models are the only models with the potential to answer the environmental questions that single-species and pure hydrodynamic models cannot (Hollowed et al. 2000, Mace 2001), the advantages of intelligent and attentive application of such models can outweigh their potential pitfalls.

One of the main criticisms aimed at ecosystem models is that their potentially immense complexity can make predictions highly uncertain (Duplisea 2000). If the model output is to be used directly to determine management actions (as in a fisheries stock assessment model), such a characteristic is clearly undesirable (Butterworth 1989). In contrast, when such models are used as a guide to possible impacts and to explore implications of alternative broad policies, this property is no longer such a problem. This is particularly true if the robustness of the conclusions is tested against a range of models incorporating different structural and parametric assumptions, representing a range of plausible alternatives about how the particular system may work. This approach permits identification of effects and policies that are robust across levels of complexity, uncertainty and underlying system and model assumptions (Reichert \& Omlin 1997, Duplisea 2000, Fulton 2001). A related use for more complex ecosystem models is as a test bed for simpler models that may be used in assessment of the system, or part of it. Applying simpler assessment models to 'data' generated from complex ecosystem models is a useful way of checking the robustness of the assessment models, and of identifying the circumstances in which it may be appropriate to use them for more 'tactical' management advice.

Using these approaches, ecosystem models have the potential to identify issues and causes beyond the bounds possible in single-species models, or even multi-species models in some cases. Management strategies implemented to achieve a certain goal may have the opposite effect if multispecies or ecosystem considerations are not included. For example, a simple predator-prey model, where seals are the predators and fishes the only type of prey, might suggest that culling seals will increase fish abundance for a given prey species. However, a more complex multispecies model might show the opposite effect if seals suppress other predators (or competitors) of that fish species (Punt \& Leslie 1995, Yodzis 2001a). Beyond even these multispecies considerations, without the inclusion of the links between the upper and lower ends of the food web and the forces driving them, erroneous conclusions may be drawn about environmental and anthropogenic impacts, as alternative explanations and scenarios are overlooked (Steele 1998, Fulton 2001, Yodzis 2001b). For example, a decline in the biomass of a herbivorous fish may indicate overfishing, but it may equally indicate degradation of their main food reserves as a result of eutrophication (Fulton 2001).

Unfortunately, although the need to integrate comprehensive biological, physical and chemical models is recognised, reconciling and reducing the dimensions of complexity required in each of the areas is a large but poorly understood task (Nihoul \& Delhez 1998, Mace 2001). Much of the handling of model complexity has been dealt with by drawing on experience from prior modelling efforts (Murray \& Parslow 1997, 1999a). As a result, the systematic understanding of the effects of model structure and detail on the performance of ecosystem models is still at an early stage. Like so many branches of mathematical modelling (Brooks \& Tobias 1996), there have been few studies of the effect of model structure on the behaviour of marine ecosystem models. As a result, this review draws on studies of model complexity in ecology, water quality and fisheries management in addition to work on ecosystem models.

\section{Model complexity in ecology: a general history}

\section{Trophic aggregation}

Optimal levels of model complexity, or appropriate degrees of trophic aggregation, remain a major problem in describing ecological systems. Thus, the study of the general properties of aggregation, and its limitations as a tool for use in model development and application, has received some attention in theoretical systems over the last $40 \mathrm{yr}$. A number of researchers have considered the effects of aggregation from a theoretical standpoint and have produced some useful guidelines (Zeigler 1976, O'Neill 1979, O'Neill \& Rust 1979, Cale \& Odell 1980, Gardner et al. 1982, Cale et al. 
1983, Iwasa et al. 1987, Bartell et al. 1988, Rastetter et al. 1992, Fulton 2001). The 2 most important guidelines are: (1) do not aggregate serially linked groups (predator and prey) (Gardner et al. 1982, Fulton 2001); (2) do not aggregate species, age classes or functional groups with rate constants more than 2- to 3-fold (Wiegert 1977, O'Neill \& Rust 1979, Cale \& Odell 1980, Gardner et al. 1982, Fulton 2001). Ignoring either of these guidelines is likely to result in a significant decline in model performance. Within the context of ecosystem models, this means that aggregating species to the level of functional groups is acceptable, but further aggregation will lead to a model that performs poorly (Fulton 2001).

\section{Construction rules}

Most studies considering the complexity of ecological models have created (subjective) rules to ensure that the most efficient model is employed (e.g. Innis \& Rexstad 1983). The most thorough of these was performed by Halfon (1983a,b) who used Bosserman's (1980) complexity measure $(\bar{c})$ to consider the effect of additional links between existing state variables (Halfon 1983a) and Hasse diagrams to investigate the structural properties of a number of different models (Halfon 1983b). Another notable, but more theoretical, approach was put forward by Iwasa et al. (1987). They gave formal mathematical rules to determine whether aggregation of model variables was possible without loss of information. While these predominantly abstract theoretical and model development studies presented some examples, they did not apply their methods to investigate the effects of complexity.

\section{Initial indications: optimal performance at intermediate model complexity}

Investigations of the effect of model structure on performance have usually occurred in less theoretical settings. One of the best analyses of the issues of model complexity and aggregation, and its impacts on subsequent management performance, was undertaken in the area of single-species fisheries assessment and management. Ludwig \& Walters $(1981,1985)$ demonstrated that for estimating the true optimal fishing policy a small and highly aggregated model can perform better than a more complex and realistic one with the same fundamental structure, even if the data were generated using the more complex model. This has been attributed to the parametric sensitivity of more detailed models, and its potential to propagate errors (Iwasa et al. 1987).
Within the more general ecological and ecosystem modelling literature, attempts to determine optimal complexity by explicitly comparing different models with each other or with data are scarce. Costanza \& Maxwell (1994) began to span the divide between development and application when they examined the relationship between resolution and the predictive capacity of models. At the other extreme, Kremer \& Kremer (1982) and Hurtt \& Armstrong (1996) both gave examples of a search for optimal complexity through practical applications (they simplified or extended an existing model and discussed whether or not there was an improvement in performance).

Overall, however, there have been only a few attempts to assess model performance with systematic changes to model complexity. One of the earliest considerations was the work by Wiegert $(1975,1977)$, who compared 5 models with differing trophic structure, levels of aggregation, spatial heterogeneity and formulation assumptions. The results suggested that the simplest of the models performed as well as the most complex, with a dip in performance for models with intermediate levels of aggregation and simplification. This pattern of results was due to inadequate handling of spatial heterogeneity and time lags in the models with intermediate levels of complexity, whereas the simplest model did not require time delays, thus avoiding that problem (Wiegert 1975). The modelling issues associated with varying degrees of model complexity in this study are strongly tied to the system being modelled and the modelling methods and assumptions employed. This may be why the relationship between complexity and performance observed by Wiegert $(1975,1977)$ has not been reported in any other study considering the effects of model complexity.

The next major study to consider the effects of model complexity (Costanza \& Sklar 1985) compared the predictive ability (judged against field data) of 87 existing (mainly multispecies) models of freshwater or shallowwater bodies using 3 indices (articulation, accuracy and effectiveness). Their work also found a non-linear relationship between model performance and complexity. The results were summarised in a plot showing that the relationship between maximum effectiveness (explanatory power) and articulation (the amount of detail in conjunction with the physical and biological scope of the model) has a humped form (Fig. 1). This finding supported anecdotal accounts from experienced modellers, particularly those involved in the International Biological Program of the early 1970s (e.g. Botkin 1977), and the conclusions from Håkanson's (1995) work on predictive multispecies models for lakes and coastal areas.

Håkanson (1995) tried to compare empirical and dynamic models by first considering the $\mathrm{r}^{2}$ values of a 


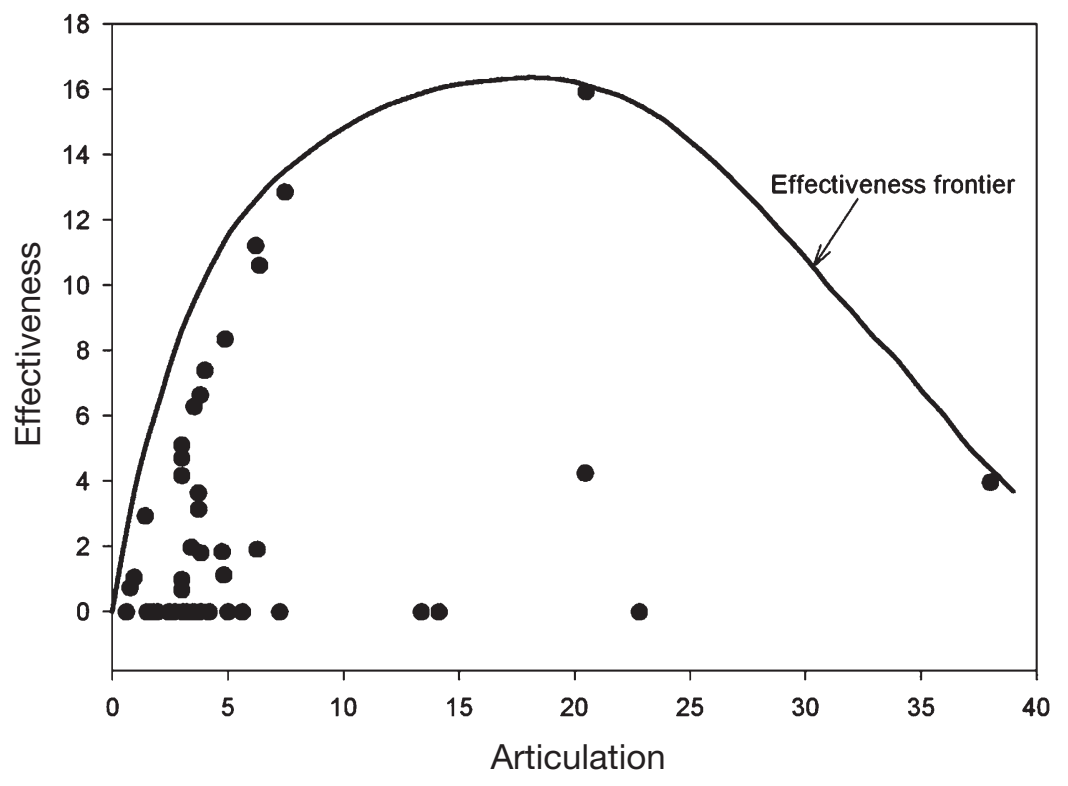

Fig. 1. Plot of articulation (measure of model complexity that has a logistic form and a scaling factor which weights the addition of a component more heavily than extra timesteps, which are in turn more heavily weighted than increased spatial resolution) against effectiveness (measure of model performance based on explanatory power) for a number of existing aquatic models redrawn from Fig. 2 in Costanza \& Sklar (1985). Effectiveness frontier: upper boundary line of maximum achieved effectiveness

number of stepwise multiple-regression models and then by examining the standard deviation of a number of additive and multiplicative models. Once again it was shown that there was a humped relationship between an indicator of performance and the number of variables included, although in this case the peak of the plot was closer to the smaller model sizes (Fig. 2). Extending this work, Håkanson (1997) examined the predictive capabilities of a range of empirical and dynamic models of the transport of radiocesium in lakes. A humped relationship between predictive power and model size was again identified.

The findings of Håkanson (1995) and those of Costanza \& Sklar (1985) provide evidence for the long-held belief that predictive power increases quickly with the elaboration of simple models, but the trend is eventually reversed as accumulating errors and process and parameter uncertainty negate any potential benefits of increased detail (Jester et al. 1977). Håkanson (1997) provided an additional explanation for the decline in performance with increased detail. When it comes to using models in a prognostic sense, large models can be prescriptive rather than predictive (Håkanson 1997) - all the extra detail can hardwire the responses rather than introduce flexibility. Further, Håkanson (1997) pointed out that the predictive power of a model is not determined by its strongest component, but by its weakest.

\section{Implications of data with low signal-to-noise ratio}

A different approach (a likelihood ratio test) was used by Yearsley \& Lettenmaier (1987) to discriminate between 3 linear compartment models with varying levels of complexity (produced by aggregating compartments). The model comparison was made on the basis of data generated from a nonlinear model of the global carbon cycle. They found that with realistic levels of measurement error even the most highly aggregated models are valid (a likelihood ratio test could not discriminate between the most aggregated compartment model and the nonlinear model used to generate the data). Similar findings have also been reported for limnological models

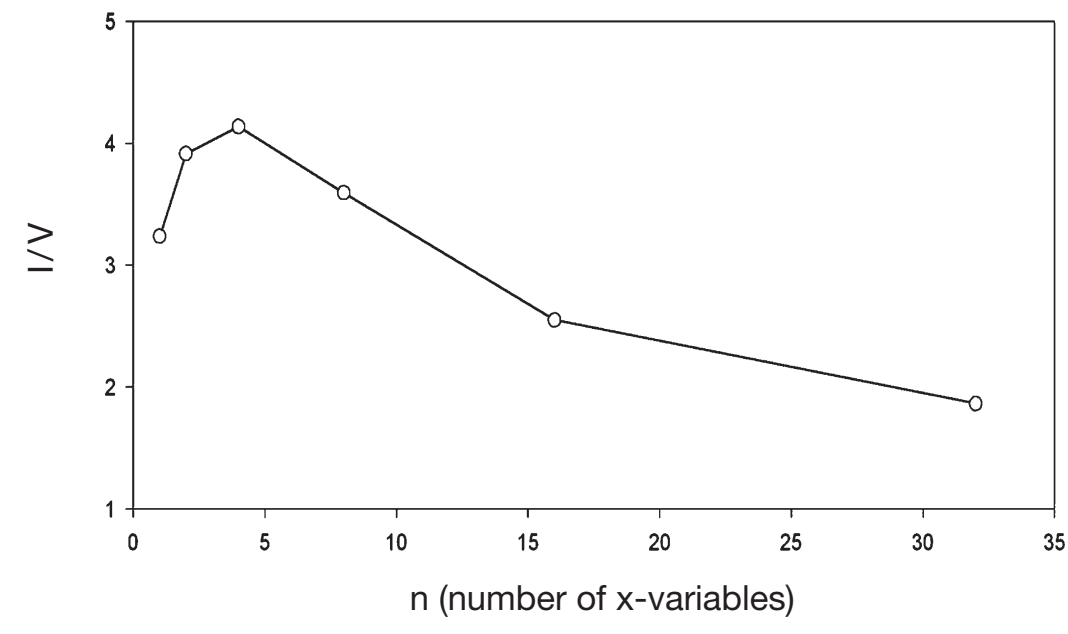

Fig. 2. Plot of predictive power $\left(I\right.$ or $\left.\mathrm{r}^{2}\right)$ /accumulated error ( $V$ or $\mathrm{SD}$ ) against the number of $\mathrm{x}$-variables (n) for predictive lake models redrawn from Fig. 6a in Håkanson (1995). I: information value, $V$ : accumulated uncertainty (relative standard deviation $=\mathrm{SD} / \mathrm{MV}$, where $\mathrm{SD}$ is the standard deviation and $\mathrm{MV}$ is the mean value) 
(van Tongeren 1995) and models of radionuclide transport in soils (Elert et al. 1999). This finding, that uncertainties in input data have a greater impact on the results than the model employed, are supported by the information theory concept of a model as a communication channel converting input data to output data. As the signal-to-noise ratio of ecological and environmental data is typically low, there is no reason to expect that a large model spanning many noisy measurements will be any better than a model which deals with fewer, more precise, measurements (Silvert 1981).

\section{Marine ecosystem models: 'deep-shallow' model comparison}

Several researchers have considered how the form of parts of models of marine systems (such as grazing and mortality) affect their dynamics (Steele \& Henderson 1992, Edwards \& Brindley 1999, Murray \& Parslow 1999b, Gao et al. 2000), but only a few have considered how the structure of entire models influences their behaviour (Hoch \& Garreau 1998, Nihoul 1998a, Nihoul \& Djenidi 1998, Yool 1998, Tett \& Wilson 2000, Murray 2001, Fulton et al. in press). The work of Hoch \& Garreau (1998) and Nihoul's body of research (Nihoul 1998a,b, Nihoul \& Delhex 1998, Nihoul \& Djenidi 1998), although primarily concerned with complexity from a hydrodynamic standpoint, should be of interest to all ecosystem modellers. Their findings highlight that ecosystem models are not only hampered by the same issues of internal complexity as any model, but they must also find a balance (or trade-off) between their various physical, chemical, geological and biological features (Hoch \& Garreau 1998, Nihoul 1998a).

While many of these studies have compared models by evaluating performance against field observations, a more systematic and theoretical approach exists. Within the field of single-species fisheries modelling, 1 methodology underlying the management strategy evaluation approach is well-established as a means of judging the performance of simpler models. The procedure tests the performance of simpler ('shallow') models against a more complex ('deep') model that captures some of the possible complexities of the real situation. Given the low signal-to-noise ratio of ecological data and the implications for model performance and interpretation, the use of the deep-shallow model comparison is very attractive. The advantage is that it allows the modeller to begin with a model that, in some sense, is known to work, and then to strip it back to identify the level of detail that is effective and most efficient. Moreover, it provides a baseline of perfect knowledge (i.e. the data generated by the deep model as opposed to that gathered from the field), and therefore enables separation of the effects of model complexity due to model structure from those due to data uncertainty. Both sides of the problem must eventually be addressed, but keeping the two separate will clarify interpretation of any results. Yool (1998), Fulton (2001) and Murray (2001) applied the deep-shallow model methodology in a more general marine ecology setting. Yool (1998) decomposed the Fasham (1993) plankton model and then reconstructed it stepwise in order to determine if a best minimum model existed. Murray (2001) compared a simplified version of the Port Phillip Bay integrated model with the original. Lastly, Fulton (2001) compared a number of ecosystem models of varying degrees of detail and complexity. Each of these studies found that some degree of simplification (of structure, trophic coverage or physical scope) is possible without degrading the model, but over-simplifying leads to a substantial decline in model performance, particularly for the purposes of predicting the effects of changing conditions. This work has provided some useful insights into 2 main areas of model construction, and these are discussed in more detail below.

While explicit investigations of model complexity are rare, there may be some very useful insights that could be drawn from a compilation of the findings of sensitivity analyses. Unfortunately, due to the scale of such a task, a meta-analysis of this kind is beyond the scope of this review.

\section{Model scope as a component of complexity}

The scope of a model is largely defined by the biological web it describes, the nutrients that are represented explicitly, its spatial resolution, and the temporal spacing of output (the model equivalent of sampling frequency in the field). Along with the particulars of model formulation (discussed in a later subsection), model scope is potentially one of the most important aspects of model complexity. Computational demands and the logistical requirements associated with collecting sufficient information to parameterise and validate ecosystem models are one of their biggest drawbacks (Silvert 1981, Sugihara et al. 1984, Lee \& Fishwick 1998). Simplifying the biological or physical scope can make a model much easier to construct, summarise and interpret. The problem is that removing too much detail can leave a model that is simple to parameterise and quick to run, but that has limited prognostic use (Tett \& Wilson 2000, Fulton 2001, Murray 2001). The challenge is to define an optimum scope that minimises complexity, but which facilitates valid and robust predictions. 


\section{Trophic complexity}

The trophic complexity of a model is concerned with 2 aspects of model structure, the number of trophic levels explicitly represented in the model and how these levels are divided into species or functional groups as defined by size classes, feeding linkages, shared predators and life-history strategies (Murray \& Parslow 1997, Pahl-Wostl 1997). Multispecies models concerned primarily with water quality or harvested species may not include all trophic levels, but assume that groups at one end of the web do not significantly influence the behaviour at the other end. In ecosystem models that may be used to consider many alternative anthropogenic scenarios, or the indirect effects of processes such as fishing, the representation of a greater number of trophic levels is probably required. Unfortunately, the problem of optimum complexity in trophic structure remains an issue, as every additional group included increases modelling and data requirements. Species-level detail could mean the complete collapse of many biogeochemical ecosystem models and, for many systems, is beyond what is possible based on empirical data. Nonetheless, without the flexibility inherent in a trophic web rather than a chain, realistic dynamics, especially under changing conditions, may be very difficult to capture (Baretta et al. 1995, PahlWostl 1997). Thus, the systematic consideration of the effects of trophic complexity on model behaviour is an important concern.

While randomly constructed food-web models have been investigated by many researchers (Gardner \& Ashby 1970, May 1973, Siljak 1974, 1976, Waide \& Webster 1976, Pimm \& Lawton 1978), within the context of ecosystem models, consideration of realistically structured webs is more enlightening (Bosserman 1982).

Changes in the behaviour of models with realistic web structure when the web is simplified by aggregation or omission of groups indicates clearly that trophic structure can be over-simplified (Sugihara et al. 1984, Christensen 1992, Optiz 1996, Pahl-Wostl 1997, Yool 1998, Fulton 2001). The simplified webs, especially those reduced to less than $25 \%$ of the size of the original model web, are not able to represent enough of the processes and interactions in the system to faithfully reproduce system dynamics, particularly when the strength of environmental or anthropogenic pressures change (Fulton 2001).

As with the general relationship between model performance and structural detail (Figs. 1 \& 2), there appears to be a nonlinear relationship between trophic complexity and behaviour. This relationship can be of 2 forms. It can be humped, like the overall relationship (Bosserman 1982, Gardner et al. 1982, Fulton 2001) or it can be in the form of a threshold-triggered stepfunction (Tett \& Wilson 2000, Fulton 2001). The second of these relationships is less common and is tied to groups with critical ecological roles, which must be explicitly represented to capture correct system dynamics.

Connectance (MacArthur 1955), the ratio of the number of strong:weak interactions in the web (McCann 2000) and redundant groups (Yachi \& Loreau 1999) have all been proposed as explanations of change in model dynamics with change in trophic complexity. However, the work by Yool (1998), Edwards (2001) and Fulton et al. 2001) suggests that none of these alone can explain the patterns of performance observed and that the identity of the components and links can be the most important determinants of performance. Thus, as with any other kind of model, it is far more important that crucial system characteristics are captured rather than rote application of a set of modelling rules.

Simple rules are not always guaranteed to work, but they are useful as a general guide. The finding that trophic complexity can be simplified to a point where models are no longer useful is probably the strongest and most useful guideline for model development. One way in which this is exemplified is the effect of trophic aggregation on model behaviour. Aggregating species into functional groups can be successful, provided the species have rate constants that differ by less than 3-fold, and have similar or common predators and prey. Pooling functional groups is less successful than omitting the least important groups entirely (Fulton 2001). This result is commensurate with the general guidelines of earlier work on the effects of model aggregation (Wiegert 1977, O'Neill \& Rust 1979, Cale \& Odell 1980, Gardner et al. 1982).

Nutrients included explicitly in models

Tett \& Wilson (2000) advised that ecosystem models should be biogeochemical, as they must conserve 1 or more elements so that the potential growth of groups can be capped. The success of ECOSIM models (Walters 1998) suggests that conservation of biomass may also be sufficient.

In biogeochemical models, it is common to use the most limiting macronutrient (carbon, nitrogen or phosphorus) as the model currency and assume that the conversion of the other nutrients conforms to the Redfield ratio (Murray \& Parslow 1997). However, this approach does not allow the model to adjust to spatial and temporal differences in nutrient availability (Baretta et al. 1995). This inability should not present a 
significant problem and will not (in general) lead to large model divergences if the system state is mesotrophic to eutrophic. This is because the other nutrients should remain in excess, even if not exactly in Redfield ratios. However, when a system is in an oligotrophic state, the dependence of the model on a single macronutrient currency can be a problem (Fulton 2001). Under these conditions the identity of the limiting nutrient may well change and the preferential remineralisation of nitrogen and phosphorus will cause significant departures from the Redfield ratio, with potentially catastrophic implications for production estimates and the dynamics of transmission up the food web. The successful application of models such as ECOPATH with ECOSIM to the open oceans (Christensen et al. 2000) suggests that models employing the conservation of biomass may not suffer as much from this problem. However, environmental influences are not usually present in such models, and if they are they are usually in the form of prescribed forcing functions (Hollowed et al. 2000). If environmental conditions became a more integrated part of these models, then the problems observed in biogeochemical models may also appear in models like ECOSIM.

\section{Physical scope}

Another important aspect of model scope that can affect model behaviour is the physical scope of the model, and in particular its spatial resolution. Many multispecies and ecosystem models (e.g. mass balance aggregate-system models such as ECOSIM) do not include any explicit spatial representation. However, space is a vital system resource in its own right in many marine systems and, as such, the way in which it is represented can have a significant impact on model dynamics and predictions (Murray 2001, Fulton 2001). Many of the model stability issues identified in ecological and ecosystem models in the past (May 1974, Pimm 1982, Cohen \& Newman 1988, Christensen et al. 2000) disappear with the introduction of explicit spatial (and thus environmental and/or ecological) heterogeneity (Johnson 1997, Johnson \& Seinen 2002, Fulton 2001). This assertion does not apply only to biogeochemical ecosystem models (such as those employed by Fulton 2001), but extends to other types of multispecies and aggregate system models (like ECOSIM). There are many examples of these models being explicitly (through the development of ECOSPACE, Walters et al. 1999) or implicitly (by separating individual model groups into inshore and offshore components; V. Christensen pers. com.) expanded to incorporate spatial partitioning. This is not to say that ecosystem models must be tied to general circulation models. Such a move would be computationally prohibitive and probably of little assistance. The box-model approach to transport processes is useful as it neglects small-scale gradients but still allows for regional differences and spatial self-structuring which, in turn, lead to the formation of distinct communities and ecological zones (Baretta et al. 1995, Fulton 2001). Even when using box-models, large numbers of cells may not be necessary if they are defined such that they resolve hydrographic discontinuities, which have important ecological implications (Nihoul \& Djenidi 1998). For example, Fulton et al. (2001) found that an 8-box model was a good compromise between the computational intensity associated with a 59-box version and the trophic self-simplification and degradation in performance associated with 3- and 1-box versions of the same model. This is another facet of model structure in which intermediate complexity is optimal.

\section{Model formulation}

The main concern of the majority of model studies considering the effect of model structure is model formulation. The way in which a model is implemented can have a large impact upon its performance and usefulness (Silvert 1981). The key areas of model formulation which have received some attention for marine system models concern process detail (particularly with regard to grazing functions and mortality terms) and the role of empirical submodels and forcing.

\section{Process detail}

Whereas physical oceanographers have a set of basic hydrodynamic equations there is no such set of equations in ecological modelling (Tett \& Wilson 2000). The problem is compounded in ecosystem models, as the modeller must integrate a variety of processes and interactions with differing characteristic temporal and spatial scales (Barthel \& Goñi 1995). Consequently, ecosystem models run the very real risk of incorporating too much detail to be comprehensible, or overcompensating in the other direction and not including enough to be realistic. Given this risk, and the increasing number of ecosystem models, there has been surprisingly little published on the effects of formulation detail on the dynamics of ecosystem models. Moreover, despite the contention that studies comparing results across a range of models incorporating alternative assumptions show the greatest promise for guiding management decisions, there have been few 
studies comparing different forms of ecosystem models (Fulton 2001).

Specific aspects of the effect of process detail will be discussed in the following subsections, but some pertinent observations about overall detail arise. The work by Håkanson (1997) and Fulton (2001) indicates that highly detailed, often physiologically based, process detail is not a pre-requisite for a successful multispecies or ecosystem model. Fulton (2001) compared the outputs and predictions of 2 ecosystem models that covered the same web and processes, but with differing levels of process detail. The Integrated Generic Bay Ecosystem Model (IGBEM) is highly physiologically detailed, while Bay Model 2 (BM2) uses the same functional groups, but much simpler assimilative equations. BM2 does have some weaknesses related to its simplified form, for example the assumption that nutrients are always in Redfield ratios causes it to perform poorly in oligotrophic conditions (where this assumption is often violated) (Fulton 2001). Despite some weaknesses, the overall performance of BM2 with regard to understanding system dynamics and qualitative responses to changing conditions is as good or better than the highly complex IGBEM, emphasing that physiological detail is not necessarily required and that simpler formulations can work. This is a boon given that BM2 requires $<50 \%$ of the number of parameters and is 30 to $60 \%$ less computationally demanding than its more complex counterpart (Fulton 2001). The amount of process detail required is only as great as that needed to successfully capture crucial system dynamics. Håkanson's (1997) result that simpler models had better predictive power than more complex versions reinforce this assertion.

The work of Tett \& Wilson (2000) on multispecies models helps to define limits to simplifying key underlying processes. They found that models which sacrifice large amounts of either biogeochemical or of ecological detail in favour of the other cannot adequately describe the dynamics of the plankton. Tett \& Wilson (2000) concluded that to realistically capture the dynamics of marine plankton the models must be biogeochemical and include trophic webs, not simple trophic chains. These minimum requirements provide realistic restrictions and alternative pathways which stabilise the models and lead to realistic simulations of seasonal changes and other observed phenomena.

The research of Murray \& Parslow (1999a) and Murray (2001) arrived at a similar conclusion. They advocated the use of simpler models as aids in the development of more sophisticated models. For example, the analysis of the simpler model indicated that explicit representation of zooplankton was necessary in multispecies plankton models and that model closure had to be carefully considered (see later subsection 'Model closure'). Ultimately however, Murray (2001) stated that the extra spatial and formulation detail included in the larger model was required for fully informed system management and to allow scientists and managers to understand and consider a number of alternative scenarios.

Studies comparing the performance or predictions of different types of model are useful for judging how robust general findings are to the underlying assumptions of the models (Fulton 2001). However, they are also an excellent source of information on the effects of process detail on model dynamics. Duplisea \& Bravington (1999) found that the results from a lengthcohort model (a multispecies forecast [MSFOR] model) and a size-spectrum mass-transfer model both led to the same conclusions regarding fisheries management strategies. Thus, for the particular question of interest, the explicit process detail of the MSFOR did not confer any advantage over the far simpler size-spectrum model. In general, size-spectrum models are a successful methodology, at least for pelagic aquatic ecosystems (Silvert 1996). However, in the context of the evaluation of management strategies, Duplisea \& Bravington (1999) recommend a few modifications, such as allowing some disaggregation into functional trophic groups and including more realistic grazing terms. The popularity of ECOSIM suggests that it may also be a successful methodology. This is supported by the finding of Fulton (2001) that, with a few exceptions, ECOSIM gave the same qualitative predictions as the biogeochemical ecosystem models IGBEM and BM2. The differences observed stem mostly from the lack of spatial detail in ECOSIM, or parts of the trophic web that are poorly known. The main differences between the biogeochemical models and ECOSIM that are a direct result of model formulation are that the biogeochemical models are not as buffered against changes in fisheries as ECOSIM, but are more buffered against changes in nutrient loading. This is a reflection of the more realistic behaviour of the low to middle trophic groups in the biogeochemical models, whereas the higher trophic groups react more sensibly in ECOSIM (Fulton 2001). This is not surprising given their respective development histories and structure, but does caution against the assumption that a formulation that works at 1 level will work at every level.

\section{Grazing terms}

General ecological research, as well as the results of more directed marine modelling, has shown that the form of grazing terms used can have important effects on overall model behaviour (May 1976, Hassell \& 
Comins 1978, Begon \& Mortimer 1986, Steele \& Henderson 1992, Gao et al. 2000, Tett \& Wilson 2000, Fulton et al. in press). Evaluation of the effects of the functional response used in plankton models, built around relatively simple food chains, indicated that they do not have as great an impact as other parts of the model (Steele \& Henderson 1992, Murray \& Parslow 1999b). In contrast, consideration of the effect of the grazing terms used in a total system model, with a complex trophic web (BM2) by Fulton et al. (in press) indicates that they can have a substantial impact on model behaviour. Fulton et al. (in press) concluded that, while there are biologically and mathematically sound arguments for the inclusion of sophisticated and dynamic functional responses, the extra parameterisation is not necessarily justified because the Holling 'Type II' response predicts the same general patterns of behaviour, and thus the same conclusions about system dynamics. Notably, linear responses (such as the Holling 'Type I') do not allow for realistic dynamics over the range of conditions of most interest in system management scenarios. Tett \& Wilson (2000) reach a similar conclusion for plankton models, whereas Gao et al. (2000) conclude that the optimal functional form will depend on the specific study and that more observations and understanding of real marine systems are required before the matter can be clarified. The latter may well be true, but for models incorporating a realistic food web, simple non-linear grazing terms may suffice due to the many other stabilising features inherent in the web (Tett \& Wilson 2000).

\section{Model closure}

The other main aspect of model formulation that has received explicit attention is the form of model closure (Steele \& Henderson 1992, Edwards \& Brindley 1999, Murray \& Parslow 1999b, Fulton et al. in press). Model closure refers to the form of the mortality term applied to the topmost group(s) explicitly included in the model. Linear and quadratic mortality terms are the most common means of dealing with model closure, and these reflect the cases when the effect of predators not included in the model are assumed to either be constant (linear mortality) or to change (quadratic mortality) with the population of their prey (the top most modelled group[s]). The specific form used can have a substantial impact on model behaviour (Murray \& Parslow 1999b).

Steady-state analysis of simple food-chain plankton models indicates that model closure can be the most important determinant of model behaviour (Steele \& Henderson 1992, Edwards \& Brindley 1999, Murray \& Parslow 1999b). In contrast, its effect on a total sys- tem model (with a complex trophic web), shows it is much less important than other aspects of model structure (Fulton et al. in press). However, even in the case of the total system model the need for the representation of higher predators (either explicitly or implicitly via quadratic mortality terms) is recognised. Unfortunately, conflicting conclusions regarding the dynamics of the highest predators (sharks, mammals and birds) when there are large changes in conditions and differential stability of the various forms of closure across a range of conditions, mean that further work on this topic is necessary (Fulton et al. in press).

Further research is also required to settle debate over the legitimacy of the use of quadratic closure. The speed of its response implies that it may represent predators who switch between prey species. In real systems, prey switching by predators has not been as readily identified as fine-scale spatial organisation (e.g. schooling) (Walters \& Kitchell 2001). Thus, proponents of the foraging arena functional response, which is based on the assumption that trophic interactions at these fine spatial scales can limit interaction rates, argue that quadratic closure is an artificial solution to issues of model stability and that use of an appropriate functional response (e.g. foraging arenas) is the real solution (C. Walters pers. comm.). However, the issue remains unresolved because the effect of spatial organisation in marine systems on interaction rates is not well elucidated empirically. Consequently, future studies that clarify the forms of functional responses in natural systems will also make important contributions to solving the issue of model closure. Until such time as empirical work determines the true form of functional responses in natural systems, it seems likely that, as a general guideline, the use of quadratic closure is acceptable regardless of the size of the implemented web (Fulton et al. in press).

\section{Forcing functions and empirical submodels}

The last facet of model formulation to have received some attention is the value and usage of empirical formulations. Empirical formulations (or empirical models as they are sometimes known) are functions that describe observed patterns or relationships in data, but without capturing real-process dynamics. These formulations have both advantages and disadvantages. They can be developed without much understanding of the phenomenon of interest, they are simple because they do not include complex causality, and they can be developed rapidly (DeCoursey 1992). All these features make empirical models attractive, and within their range of applicability they can often provide 
better predictive power than dynamic models (Håkanson 1997). Their limiting feature is that many domains of interest can be outside the range of applicability. This, along with the arbitrary nature of these models and the associated risk of adopting a misleading approach or false assumptions, can mean they are less than ideal (DeCoursey 1992).

Within the realm of marine ecosystem models, the model development choices are more complex than empirical versus purely process models because empirical models can play a role within dynamicprocess models. Given that the understanding of some components of marine ecosystems are poor (e.g. the processes and forces shaping the behaviour of the benthic infauna), the use of empirical submodels for the least known parts of the system is an attractive alternative. The inappropriate use of simple forcing functions can lead to very poor model performance, while the use of a structured empirical submodel can work very well (Fulton 2001). Alternatively, the use of an empirical representation of an important process can prevent degradation of model performance. This is especially true if the causal mechanisms for the process are poorly known, or if explicit inclusion of the details of the mechanism is beyond the scope of the model or the capability of the available data or computational resources. For example, the empirically based bacteria-denitrification submodel employed in BM2 is a vast improvement over another process-based attempt at modelling bacteria and denitrification (Fulton 2001), both of which components are still poorly known in many respects.

\section{Model performance under changing conditions}

Use of ecosystem models to gain insight into a system and to indicate (at least) qualitative trends associated with a change in 'forcing' conditions is one of their most useful roles. It is also at this point that assumptions underlying the model formulation can have their greatest impacts. Thus, confirmatory comparison of models is strongly advocated. A comparison of 3 ecosystem models (ECOSIM, BM2 and IGBEM) by Fulton (2001) indicated that overall model structure and formulation can provide the same general predictions under changing conditions, but still predict some potentially important differences in specific cases. For example, applying a fisheries management strategy developed purely to maximise economic gains to all 3 models produced predictions that coincided for the majority of the biological components in all the models and there was agreement between at least 2 of the models for all the components except detritus. However, the 3 models all gave different results for detritus
(ECOSIM predicted no change, BM2 predicted a decline and IGBEM an increase). Given the role of detritus as a long-term storage of nutrients in enclosed bays like that modelled, such a range of outcomes is a crucial result. This illustrates how conclusions drawn from different models can be very different for particular components of a system, even when the models generally agree overall.

The effects of implemented process detail and model scope are usually most apparent under changing conditions such as changing nutrient loads or fishing pressures. A change in conditions or pressures on a system may be beyond the range of applicability of an empirical model or may expose a flaw in a chosen formulation (Fulton 2001, Murray 2001). During an investigation of the effect of model structure on the behaviour of ecosystem models, Fulton (2001) repeatedly found that formulations of varying complexity can have very similar dynamics or show only small divergences under baseline conditions, but show much larger differences under altered nutrient loads or fishing pressures. For example, the problems associated with restricted spatial resolution, or highly simplified trophic structures, or grazing and mortality terms that do not include some form of limitation, all lead to poor performance under changing conditions. Thus, performance under changing conditions is an important measure of how robust model behaviour is to the level of complexity employed in a particular aspect of model structure or scope.

Unfortunately, model failure need not be expressed in such an obvious way as instability or aberrant behaviour. A model that incorrectly specifies some process (like feeding or mortality) or has a scope that is too restricted may still appear to have acceptable behaviour in relation to its state under current conditions, but the predicted behaviour under altered conditions may be incorrect. For example, compared with the 59-box version, the lack of spatial structure in the 1-box model evaluated in Murray (2001) caused it to overestimate the nutrient loads that Port Phillip Bay could tolerate by $30 \%$. This is a large problem if this version of the model is used to guide management of nutrient loading and water quality in this bay.

\section{DISCUSSION AND CONCLUSIONS}

The multitude of links and processes that make up a real ecosystem mean that the ultimate effects of anthropogenic actions will probably be much wider than expected and, because of inevitable non-linearities, may even lead to counterintuitive outcomes. Ecosystem models are a prime candidate as a tool to aid in the understanding of these potential outcomes. This does not mean that they do not have potential 
drawbacks associated with their own size and complexity, but careful consideration of these problems and the intelligent application of the models can avoid or minimise many of these problems. However, greater understanding of the effects of model structure and scope on model performance are necessary. This is particularly the case if we are to avoid the situation where frustration resulting from poorly structured ecosystem models, or the inappropriate use of existing ecosystem models, leads us to reject the modelling approach altogether.

Studies of the effect of model structure that have already taken place indicate that there is a humped form to the relationship between model detail and performance (Costanza \& Sklar 1985, Håkanson 1995, 1997, Fulton 2001). Too much complexity leads to too much uncertainty and problems with interpretation of the model's dynamics and predictions, while too little detail results in models that cannot produce realistic behaviours. These studies have also identified some important guidelines which can usefully extend or augment those proposed in earlier works on ecological models (Wiegert 1977, O'Neill \& Rust 1979, Cale \& Odell 1980, Gardner et al. 1982, Halfon 1983a,b, Innis \& Rexstad 1983, Iwasa et al. 1987): (1) Explicit physiological detail of every trophic group is not always necessary. However, the use of explicit physiological detail can be important in certain circumstances (such as oligotrophic conditions when simple assumptions about nutrient uptake and the ratio of limiting nutrients are violated). (2) If an important process or linkage (e.g. to an external web) is poorly known, or is not explicitly represented in the model, then an empirical representation should be included in its place. This can avoid introducing uncertainty without risking the degradation of performance associated with neglecting a crucial aspect of a system. (3) Some level of spatial resolution is likely to be necessary for adequate performance of the model. A 1-box model is unlikely to be sufficient, as space is itself an important and selforganising system resource. This is particularly true in systems where benthic groups are important. Moreover, there must be enough spatial resolution in the model to capture the major physical characteristics of the system. Trophic self-simplification of the tropic web (the loss of 1 or more components from the web) is often a good indicator that spatial representation is overly restricted. (4) The inclusion of a complete trophic web at the level of species is neither necessary nor desirable, but the way in which the web is handled is critical. The use of functional groups (defined based on size and shared predators and prey) is a successful means of representing the system web realistically (particularly if some age or size structure is included for the highest groups). Aggregation beyond the level of functional groups is ill-advised, and omission of the least important groups is a better strategy if further simplification is necessary. Moreover, simplifying a model web (which represents the food web of an entire system aggregated to the level of functional groups) to less than 20 to $25 \%$ of its original size is rarely beneficial, as representing the distinctions between large and small or mobile and sedentary groups may be crucial. (5) Quadratic closure of the topmost parts of the trophic web is a successful method of closing the web, regardless of its size, but there is some debate about whether this solution is ecologically justified. The explicit inclusion of the highest predators may only be necessary when they are of direct interest. (6) The form of the grazing functions used must be given careful consideration so that they contain enough flexibility without introducing extraneous detail. Holling Type I responses are unlikely to be sufficient (especially under changing conditions), but the more complex Holling type functions (e.g. Type II) may be acceptable. More sophisticated responses, incorporating more behavioural dynamics (e.g. balancing predator avoidance with the need to forage) may be required in some circumstances, but the value of their inclusion should be checked.

The issue of the effect of model complexity on model behaviour and performance is far from being a closed chapter, especially with regard to ecosystem models. Within the context of trophic complexity and ECOSIM, Walters stresses that '... this [exploration of the effects] is a really crucial issue that has not yet been systematically explored by any of the science groups involved in ECOSIM modeling' (C. Walters pers. comm.). However, this point is not restricted to trophic complexity or ECOSIM, but pertains to all facets of model structure and the many methodologies and ecosystem models currently in use. The work covered in this review is a useful start, but there is still much ground to be covered.

Acknowledgements. The authors are indebted to Robert Bell, Andy Edwards, Lars Håkanson, Jacques Nihoul, Sandy Murray, John Parslow, Keith Sainsbury, Bill Silvert, Carl Walters and Andy Yool for their willingness to participate in discussions of model complexity. The authors would also like to thank Ian Ball for his comments on a draft of this paper. The CSIRO Division of Marine Research and the University of Tasmania (funds awarded to C. R. J) provided financial support for this work.

\section{LITERATURE CITED}

Andersen KP, Ursin E (1977) A multispecies extension to the beverton and holt theory of fishing, with accounts of phosphorus circulation and primary production. Medd Danm Fisk-Havunders NS 7:319-435 
Baretta JW, Ebenhöh W, Ruardij P (1995) The European Regional Seas Ecosystem Model, a complex marine ecosystem model. Neth J Sea Res 33:233-246

Baretta-Bekker JG, Baretta JW (eds) (1997) Special issue: European Regional Seas Ecosystem Model II. J Sea Res 38

Bartell SM, Cale WG, O'Neill RV, Gardner RH (1988) Aggregation error: research objectives and relevant model structure. Ecol Model 41:157-168

Barthel KG, Goñi R (1995) Preface. Neth J Sea Res 33:229

Bax N, Eliassen JE (1990) Multispecies analysis in Balsfjord, northern Norway: solution and sensitivity analysis of a simple ecosystem model. J Cons Int Explor Mer 47: 175-204

Beck MB (1999) Coping with ever larger problems, models, and databases. Water Sci Technol 39:1-11

Begon M, Mortimer M (1986) Population ecology: a unified study of animals and plants. Blackwell Science Publications, London, Melbourne, Boston

Bosserman RW (1980) Complexity measures for assessment of environmental impact in ecosystem networks. In: Proceedings of the Pittsburgh Conference of Modelling and Simulation, Pittsburgh, PA, USA, April 20-23, 1980, p 811-820

Bosserman RW (1982) Structural comparisons for four lake ecosystem models. In: Troncale L (ed) Systems science and science, Proceedings of the 26th Annual Meeting of the Society for General Systems Research with the American Association for the Advancement of Science, Washington, D.C., January 5-9, 1982. Society for General Systems Research: Louisville, Kentucky, p 559-568

Botkin DB (1977) Bits, bytes, and IBP. BioScience 27:385

Breckling B, Müller F (1994) Current trends in ecological modelling at the 8th ISEM conference on the state-of-theart. Ecol Model 75/76:667-675

Brooks RJ, Tobias AM (1996) Choosing the best model: level of detail, complexity, and model performance. Mathl Comput Model 24:1-14

Butterworth DS (1989) The Benguela Ecology Programme: successful and appropriate? S Afr J Mar Sci 85:633-643

Cale WG, Odell PL (1980) Behaviour of aggregate state variable in ecosystem models. Math Biosci 49:121-137

Cale WG, O'Neill RV, Gardner RH (1983) Aggregation error in nonlinear ecological models. J Theor Biol 100:539-550

Christensen V (1992) Network analysis of trophic interactions in aquatic ecosystems. PhD thesis, Royal Danish School of Pharmacy, Copenhagen

Christensen V, Walters CJ, Pauly D (2000) ECOPATH with ECOSIM: a user's guide. October 2000 edn. Fisheries Centre, University of British Columbia, Vancouver

Cohen JE, Newman CM (1988) Dynamic basis of food web organization. Ecology 69:1655-1664

Costanza R, Maxwell T (1994) Resolution and predictability: an approach to the scaling problem. Land Ecol 9:47-57

Costanza R, Sklar FH (1985) Articulation, accuracy and effectiveness of mathematical models: a review of freshwater wetland applications. Ecol Model 27:45-68

DeCoursey DG (1992) Developing models with more detail: do more algorithms give more truth? Weed Technol 6: 709-715

Duplisea DE (2000) The ecological hierarchy, model complexity, predictive ability and robust management. In: Report on the Young Scientists Conference on Marine Ecosystem Perspectives, ICES Cooperative Research Report No. 240. International Council for the Exploration of the Sea, Copenhagen, p 59-60

Duplisea DE, Bravington MV (1999) Harvesting a size-structured ecosystem. ICES 1999/Z:01 Ecosystem management.
International Council for the Exploration of the Sea, Copenhagen

Edwards AM (2001) Adding detritus to a nutrientphytoplankton-zooplankton model: a dynamical-systems approach. J Plankton Res 23:389-413

Edwards AM, Brindley J (1999) Zooplankton mortality and the dynamical behaviour of plankton population models. Bull Math Biol 61:303-339

Elert M, Butler A, Chen J, Dovlete C and 5 others (1999) Effects of model complexity on uncertainty estimates. J Environ Radioact 42:255-270

Fasham MJR (1993) Modelling the marine biota. In: Heimann $M$ (ed) The global carbon cycle. Springer-Verlag, New York

Fransz HG, Mommaerts JP, Radach G (1991) Ecological modelling of the North Sea. Neth J Sea Res 28:67-140

Fulton EA (2001) The effects of model structure and complexity on the behaviour and performance of marine ecosystem models. PhD thesis, School of Zoology, University of Tasmania, Hobart, Australia

Fulton EA, Smith ADM, Johnson CR (in press) Mortality and predation in ecosystem models: is it important how these are expressed? Ecol Model

Gao H, Wei H, Sun W, Zhai X (2000) Functions used in biological models and their influences on simulations. Indian J Mar Sci 29:230-237

Gardner MR, Ashby WR (1970) Connectance of large dynamic (cybernetic) systems: critical values for stability. Nature 228:784

Gardner RH, Cale WG, O'Neill RV (1982) Robust analysis of aggregation error. Ecology 63:1771-1779

Håkanson L (1995) Optimal size of predictive models. Ecol Model 78:195-204

Håkanson L (1997) Modelling of radiocesium in lakes - on predictive power and lessons for the future. Stud Environ Sci 68:3-45

Halfon E (1979) Computer-based development of large-scale ecological models: problems and prospects. In: Innis GS, O'Neill RV (eds) Systems analysis of ecosystems. International Co-operative Publishing House, Fairland, MD

Halfon E (1983a) Is there a best model structure? I. Modeling the fate of a toxic substance in a lake. Ecol Model 20: $135-152$

Halfon E (1983b) Is there a best model structure? II. Comparing the model structures of different fate models. Ecol Model 20:153-163

Hassell MP, Commins HN (1978) Sigmoid functional responses and population stability. Theor Popul Biol 14:62-67

Hoch T, Garreau P (1998) Phytoplankton dynamics in the English Channel: a simplified three-dimensional approach. J Mar Syst 16:133-150

Hollowed AB, Bax N, Beamish R, Collie J, Fogarty M, Livingston P, Pope J, Rice JC (2000) Are multispecies models an improvement on single-species models for measuring fishing impacts on marine ecosystems? ICES J Mar Sci 57: 707-719

Hurtt GC, Armstrong RA (1996) A pelagic ecosystem model calibrated with BATS data. Deep-Sea Res Part II Top Stud Oceanogr 43:653-683

Innis GS, Rexstad E (1983) Simulation and model simplification techniques. Simulation 41:7-15

Iwasa Y, Andreasen V, Levin S (1987) Aggregation in model ecosystems. I: Perfect aggregation. Ecol Model 37:287-302

Jester DB Jr, Garling DL Jr, Tipton AR, Lackey RT (1977) A general population dynamics theory for largemouth bass. FWS 1-77, Virgina Polytechnic Institute and State University, Blacksburg, VA 
Johnson CR (1997) Self-organizing in spatial competition systems. In: Klomp NI, Lunt ID (eds) Frontiers in ecologybuilding the links. Elsevier, Amsterdam, p 245-263

Johnson CR, Seinen I (2002) Selection for restraint in competitive ability in spatial competition systems. Proc R Soc Lond Ser B Biol Sci 269:655-663

Jørgensen SE (1994) Fundamentals of ecological modelling, 2nd edn Developments in environmental modelling. 19. Elsevier, Amsterdam

Jørgensen SE, Patten BC, Straškraka M (1992) Ecosystems emerging: toward an ecology of complex systems in a complex future. Ecol Model 62:1-27

Kremer JN, Kremer P (1982) A three-trophic level estuarine model: synergism of two mechanistic simulations. Ecol Model 415:145-157

Lee K, Fishwick PA (1998) Generation of multimodels and selection of the optimal model for real-time simulation. In: Sisti AF (ed) Enabling technology for simulation science II, Proc SPIE 3369:164-175

Ludwig D, Walters CJ (1981) Measurement errors and uncertainty in parameter estimates for stock recruitment. Can J Fish Aquat Sci 38:711-720

Ludwig D, Walters CJ (1985) Are age-structured models appropriate for catch-effort data? Can J Fish Aquat Sci 42: 1066-1072

MacArthur RH (1955) Fluctuations of animal populations and a measure of community stability. Ecology 36:533-536

Mace PM (2001) A new role for MSY in single-species and ecosystem approaches to fisheries stock assessment and management. Fish Fish 2:2-32

May RM (1974) Stability and complexity in model ecosystems, 2nd edn. Monographs in population biology, No. 6. Princeton University, Princeton, NJ

May RM (1973) Stability and complexity in model ecosystems. Princeton University Press, Princeton, NJ

May RM (1976) Theoretical ecology. Saunders, Philadelphia

McCann KS (2000) The diversity-stability debate. Nature 405: $228-233$

Murray AG (2001) The use of simple models in the design and calibration of a dynamic 2D model of a semi-enclosed Australian bay. Ecol Model 136:15-30

Murray A, Parslow J (1997) Port Phillip Bay integrated model: final report. Technical report No. 44. Port Phillip Bay Environmental Study. CSIRO, Canberra, Australia

Murray AG, Parslow JS (1999a) Modelling of nutrient impacts in Port Phillip Bay - a semi-enclosed marine Australian ecosystem. Mar Freshw Res 50:597-611

Murray AG, Parslow JS (1999b) The analysis of alternative formulations in a simple model of a coastal ecosystem. Ecol Model 119:149-166

Nihoul JCJ (1998a) Optimum complexity in ecohydrodynamic modelling: an ecosystem dynamics standpoint. J Mar Syst $16: 3-5$

Nihoul JCJ (1998b) Modelling marine ecosystems as a discipline in Earth Science. Earth-Sci Rev 44:1-13

Nihoul JCJ, Delhez EJM (1998) Preface, 28th International Liège Colloquium on Ocean Hydrodynamics: Liège, May 6-10, 1996: Modelling hydrodynamically dominated marine ecosystems. J Mar Syst 16:1-2

Nihoul JCJ, Djenidi S (1998) Chapter 18: Coupled physical, chemical and biological models. In: Brink KH, Robinson AR (eds) The sea. John Wiley \& Sons, New York

O'Neill RV (1975) Modeling in the eastern deciduous forest biome. In: Patten BC (ed) System analysis and simulation in ecology III. Academic Press, New York, London, p 49-72

O'Neill RV (1979) Transmutations across hierarchical levels.
In: Innis GS O'Neill RV (eds) Systems analysis of ecosystems. International Co-operative, Fairland, MD, p 59-78

O'Neill RV, Rust B (1979) Aggregation error in ecological models. Ecol Model 7:91-105

Optiz S (1996) Trophic interactions in Caribbean coral reefs. ICLARM Tech Rep 43

Pahl-Wostl C (1997) Dynamic structure of a food web model: comparison with a food chain model. Ecol Model 100: 103-123

Patten BC, Egloff DA, Richardson TH (1975) Total ecosystem model for a cove in Lake Texoma. In: Patten BC (ed) System analysis and simulation in ecology III. Academic Press, New York, London

Pimm SL (1982) Food webs. Chapman \& Hall, London

Pimm SL, Lawton JH (1978) On feeding on more than one trophic level. Nature 275:542-544

Punt AE, Leslie RW (1995) The effects of future consumption by the Cape fur seal on catches and catch rates of the Cape hakes. 1. Feeding and diet of the Cape hakes Merluccius capensis and $M$. paradoxus. S A J Mar Sci 16:37-55

Rastetter EB, King AW, Cosby BJ, Hornberger GH, O'Neill RV, Hobbie JH (1992) Aggregating fine-scale ecological knowledge to model coarser-scale attributes of ecosystems. Ecol Appl 2:55-70

Reichert P, Omlin M (1997) On the usefulness of overparameterized ecological models. Ecol Model 95:289-299

Sainsbury K, Punt AE, Smith ADM (2000) Design of operational management strategies for achieving fishery ecosystem objectives. ICES J Mar Sci 57:731-741

Siljak DD (1974) Connective stability of complex ecosystems. Nature 249:280

Siljak DD (1976) When is a complex ecosystem stable? Math Biosci 25:25-50

Silvert WL (1981) Principles of ecosystem modelling. In: Longhurst AR (ed) Analysis of marine ecosystems. Academic Press, New York, p 651-676

Silvert WL (1996) Size-aggregation in models of aquatic ecosystems. Sci Total Environ 183:107-114

Steele JH (1998) From carbon flux to regime shift. Fish Oceanogr 7:176-181

Steele JH, Henderson EW (1992) The role of predation in plankton models. J Plank Res 14:157-172

Sugihara G, Garcia S, Gulland JA, Lawton JH and 7 others (1984) Ecosystem dynamics: Group Report. In: May RM (ed) Exploitation of marine communities, Dahlem Konferenzen 1984. Springer-Verlag, Berlin, p 131-153

Tett P, Wilson H (2000) From biogeochemical to ecological models of marine microplankton. J Mar Syst 25:431-446

van Tongeren OFR (1995) Data analysis or simulation model: a critical evaluation of some methods. Ecol Model 78: $51-60$

Waide JB, Webster JR (1976) Engineering systems analysis: applicability to ecosystems. In: Patten BC (ed) Systems analysis and simulation in ecology. IV. Academic Press, New York, p 329-371

Walters C (1998) ECOSIM and ECOSPACE: basic considerations. In: Pauly D, Weingartner G (eds) Use of ECOPATH and ECOSIM to evaluate strategies for sustainable exploitation of multi-species resources. Proceedings of a Workshop held March 25-27, 1998. Fisheries Centre, University of British Columbia: Vancouver, Canada, p 11-14

Walters C, Kitchell JF (2001) Cultivation/depensation effects on juvenile survival and recruitment: implications for the theory of fishing. Can J Fish Aquat Sci 58:39-50

Walters C, Christensen V, Pauly D (1997) Structuring dynamic models of exploited ecosystems from trophic massbalance assessments. Rev Fish Biol Fish 7:139-172 
Walters C, Pauly D, Christensen V (1999) ECOSPACE: prediction of mesoscale spatial patterns in trophic relationships of exploited ecosystems, with emphasis on the impacts of marine protected areas. Ecosystems 2: $539-554$

Watt KEF (1975) Critique and comparison of biome ecosystem modeling. In: Patten BC (ed) System analysis and simulation in ecology, III. Academic Press: New York, London, p 139-152

Wiegert RG (1975) Simulation modeling of the algal-fly components of a thermal ecosystem: effects of spatial heterogeneity, time delays, and model condensation. In: Patten BC (ed) System analysis and simulation in ecology, III. Academic Press, New York, p 157-181

Wiegert RG (1977) A model of a thermal spring food chain. In: Hall C, Day JW (eds) Ecosystem modelling in theory and practice. Wiley \& Sons, New York, p 290-315

Editorial responsibility: Otto Kinne (Editor),

Oldendorf/Luhe, Germany
Yachi S, Loreau M (1999) Biodiversity and ecosystem functioning in fluctuating environments: the insurance hypothesis. Proc Natl Acad Sci USA 96:1463-1468

Yearsley JR, Lettenmaier DP (1987) Model complexity and data worth: an assessment of changes in the global carbon budget. Ecol Model 39:201-226

Yodzis P (2001a) Must top predators be culled for the sake of fisheries? Trends Ecol Evol 16:78-84

Yodzis P (2001b) Culling predators to protect fisheries: a case of accumulating uncertainties-response. Trends Ecol Evol $16: 282-283$

Yool A (1998) The dynamics of open-ocean plankton ecosystem models. PhD thesis, Ecology and Epidemiology, Department of Biological Sciences, University of Warwick

Zeigler BP (1976) The aggregation problem. In: Patten BC (ed) System analysis and simulation in ecology, IV. Academic Press, New York, p 299-311

Submitted: March 6, 2002; Accepted: October 25, 2002 Proofs received from author(s): April 24, 2003 